\title{
COMPETÊNCIAS EMPREENDEDORAS NO CONTEXTO DO ENSINO SUPERIOR: CONSTRUÇÃO DE UMA ESCALA DE AVALIAÇÃO
}

Luciana Padovez Cualheta ${ }^{1}$

Gardenia Abbad $^{1}$

Cristiane Faiad ${ }^{1}$

Cândido Vieira Borges Junior²

${ }^{1}$ Universidade de Brasília

${ }^{2}$ Universidade Federal de Goiás 


\section{COMPETÊNCIAS EMPREENDEDORAS NO CONTEXTO DO ENSINO SUPERIOR: CONSTRUÇÃO DE UMA ESCALA DE AVALIAÇÃO}

\section{Resumo}

O presente artigo apresenta o processo de elaboração e validação de uma escala que avalia as competências empreendedoras desenvolvidas por um curso de extensão universitário. Tal curso utiliza metodologias como Design Thinking, desenvolvimento de clientes, modelagem de negócios e Lean Startup, com aulas práticas e ativas. Para elaboração e validação da escala, foram feitas análises documentais, grupos focais, validação por juízes, validação semântica e validação empírica com 182 respondentes. A escala apresentou evidências de validade. A principal contribuição propostas pelo artigo é a apresentação de uma escala capaz de mensurar as competências empreendedoras desenvolvidas por estudantes de cursos ou disciplinas de empreendedorismo, uma vez que as escalas existentes são focadas nos donos de empresas. Ainda, a escala pode ser replicada para avaliação de outros cursos ou disciplinas de empreendedorismo e seu processo de construção e validação pode ser replicado para a elaboração de novos instrumentos para avaliação de outras disciplinas.

Palavras-chave: empreendedorismo. ensino de empreendedorismo. competências empreendedoras. avaliação. 


\section{Introdução}

O ensino de empreendedorismo enquanto método propõe a utilização de uma série de estratégias capazes de estimular a ação e a criação. Não basta que o aluno pense sobre, fale sobre ou entenda o que é empreendedorismo. Ele precisa agir, aplicar e testar (Neck \& Greene, 2011). Diante disso, o ensino de empreendedorismo tem focado em intervenções práticas e combinado metodologias tradicionais de ensino com ações como teste de hipóteses (Ries, 2011), modelagem de negócios (Osterwalder \& Pigneur, 2010) e desenvolvimento de clientes (Blank \& Dorf, 2012) para estimular o desenvolvimento de competências empreendedoras pelos alunos.

Essas metodologias estimulam a experimentação, a obtenção de feedbacks, a elaboração de protótipos e produtos mínimos viáveis, a validação das ideias de negócios por meio de contato com possíveis clientes, fornecedores, parceiros e fabricantes e constantes adaptações no produto ou serviço para aumentar as chances de sucesso de um novo negócio (Osterwalder \& Pigneur, 2010; Ries, 2011; Blank \& Dorf, 2012).

Parte das escalas de competências empreendedoras encontradas na literatura (Chandler \& Jansen, 1992; Man \& Lau, 2002; Man, Lau \& Snape, 2008; Mitchelmore \& Rowley, 2010; Kyndt \& Baert, 2015) foram elaboradas para mensurar as competências de donos de negócios já existentes. Dessa forma, não abrangem as competências exigidas pelas novas metodologias citadas.

Além disso, por terem sido elaboradas avaliando principalmente competências de empreendedores que já tem um negócio, tais escalas podem ser consideradas inadequadas para mensurar as competências desenvolvidas por alunos de cursos ou disciplinas de empreendedorismo, uma vez que o contexto de aprendizagem e as competências apropriadas para o momento da trajetória do empreendedor que pretende ou está iniciando a criação de um novo negócio são diferentes daqueles que estão atuando na gestão de um negócio novo ou estabelecido (Mitchelmore \& Rowley, 2010). Embora os resultados de aprendizagem sejam o desenvolvimento de competências, que são observáveis e centradas em comportamentos, a maior parte das pesquisas avaliam os efeitos do ensino de empreendedorismo por meio da intenção de empreender, o que é insuficiente para compreender seus reais resultados (Fayolle, 2013).

Diante do exposto, o presente artigo apresenta o processo de elaboração e validação de uma escala que avalia as competências empreendedoras desenvolvidas no contexto de um curso de extensão universitário. Tal curso utiliza metodologias como Design Thinking, desenvolvimento de clientes, modelagem de negócios e Lean Startup, com aulas práticas e ativas. A escala poderá ser utilizada para avaliar as competências desenvolvidas pelo aluno no curso, ao invés de se pesquisar sua intenção de empreender.

Para elaboração e validação da escala, foram feitas análises documentais, grupos focais, validação por juízes, validação semântica e validação empírica com 182 respondentes. Os resultados indicam que a escala possui evidências de validade. As principais contribuições propostas pelo artigo dizem respeito ao avanço na teoria de competências empreendedoras, ao identificar competências relacionadas às metodologias emergentes. Além disso, apresenta uma escala capaz de mensurar as competências empreendedoras desenvolvidas por estudantes de cursos ou disciplinas de empreendedorismo, uma vez que as escalas existentes são focadas nos

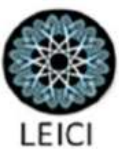


donos de empresas. Ainda, a escala pode ser replicada para avaliação de outros cursos ou disciplinas de empreendedorismo e seu processo de construção e validação pode ser replicado para a elaboração de novos instrumentos para avaliação de outras disciplinas.

\section{Referencial Teórico}

\subsection{Competências Empreendedoras}

Competências empreendedoras são apresentadas por indivíduos que iniciam e transformam negócios e costumam ser relacionadas com o nascimento, a sobrevivência, o desempenho e crescimento de negócios (Mitchelmore \& Rowley, 2013). Bird (1995) define competências empreendedoras como as características, conhecimentos, motivações e habilidades que resultam na criação e sobrevivência de empresas. Já para Man, Lau e Snape (2008) os empreendedores competentes são aqueles que identificam oportunidades de inovação, desenvolvem novos produtos e serviços, encontram formas de aumentar a qualidade e reduzir custos e assim, melhorando o desempenho das empresas (Man, Lau, \& Snape, 2008).

Lans et al. (2008) relaciona as competências empreendedoras com a identificação e exploração de oportunidades. Segundo os autores, as competências vão além da elaboração do plano de negócios e dizem respeito à capacidade de encontrar e convencer investidores a aportar capital no negócio e à criação de bom relacionamento com clientes e fornecedores. Segundo Mitchelmore e Rowley (2010), nas pequenas e médias empresas, as competências empreendedoras são usadas pelos fundadores e funcionários para combinar recursos da melhor forma possível, garantindo que os resultados da empresa sejam alcançados.

Baseados na teoria de competitividade, Man, Lan e Chang (2002) relacionaram competências com desempenho das empresas e propuseram um modelo de competências empreendedoras, com base naquelas encontradas na literatura. As competências foram divididas em seis grandes áreas: (1) competências de oportunidade, relacionadas à capacidade de reconhecer e desenvolver oportunidades de mercado, (2) competências de relacionamento, que se referem às capacidades do empreendedor de fazer contatos, se comunicar, se relacionar com pessoas e persuadi-las, (3) competências conceituais, que dizem respeito a várias habilidades, tais como a tomada de decisão, assumir riscos, inovar e outros, (4) competências de organização, que se referem a como o empreendedor organiza os recursos internos e externos, (5) competências estratégicas, relacionadas com a formulação, implementação e acompanhamento de estratégias para a empresa, (6) competências de comprometimento, que são as que levam o empreendedor a persistir no negócio.

Para confirmar esses resultados, Man et al. (2008) desenvolveram um instrumento, a partir de um estudo qualitativo, no qual 19 empreendedores de sucesso foram entrevistados. $\mathrm{O}$ instrumento tinha 53 itens e foi aplicado a 153 donos de pequenas e médias empresas em Hong Kong para identificar quais eram as competências empreendedoras que empreendedores de sucesso possuem. Por meio da análise fatorial, dez fatores de competências empreendedoras foram obtidos: de relacionamento, analíticas, de inovação, de oportunidades, estratégicas, humanas, operacionais, de comprometimento, de persistência e de aprendizagem.

Em sua revisão de literatura, Mitchelmore e Rowley (2010) propuseram um resumo das competências empreendedoras identificadas em quatro grupos: competências empreendedoras, competências de gestão de negócios, competências de relacionamentos humanos e

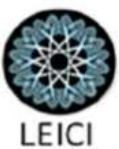


competências conceituais. Morris et al. (2013), por sua vez, argumentam que as competências empreendedoras não têm distinções claras em relação as competências de gestão e, na tentativa de entender quais competências são críticas para o sucesso e bom desempenho do negócio, conduziram três análises junto a especialistas, utilizando o método Delphi até obter o consenso. $\mathrm{O}$ estudo identificou treze grupos de competências empreendedoras: reconhecimento de oportunidades, avaliação de oportunidades, gestão do risco, visão de futuro, perseverança, solução criativa de problemas, captação de recursos, guerrilha, criação de valor, foco, resiliência, autoeficácia, construção e utilização de rede de contatos.

Ainda, Kyndt e Baert (2015) desenvolveram e testaram um instrumento para identificar as competências empreendedoras consideradas mais importantes. As competências essenciais identificadas pelas autoras foram: perseverança, autoconhecimento, orientação para aprendizagem, busca de retorno, capacidade de tomar decisões, capacidade de planejar o futuro, independência, persuasão, criação de redes de relacionamento, identificação de oportunidades, conhecimento do mercado, conduta social e ambientalmente responsável. A Tabela 1 resume as principais competências empreendedoras identificadas na literatura.

Tabela 1

Competências empreendedoras identificadas na literatura

\begin{tabular}{|c|c|}
\hline Competência & Autores \\
\hline Análise do mercado & $\begin{array}{l}\text { Man et al. (2008); Morris et al. (2013); Kyndt and } \\
\text { Baert (2015) }\end{array}$ \\
\hline Aprendizagem & Kyndt and Baert (2015); Man et al. (2008) \\
\hline Autoconhecimento & Kyndt and Baert (2015) \\
\hline Autoeficácia & Morris et al. (2013) \\
\hline Comprometimento & Man and Lau (2002); Man et al. (2008) \\
\hline Conceituais & $\begin{array}{l}\text { Chandler and Jansen (1992); Man and Lau (2002); } \\
\text { Mitchelmore and Rowley (2010); Morris et al. (2013) }\end{array}$ \\
\hline Estratégicas & Man and Lau (2002); Man et al. (2008); Kyndt and Baert (2015) \\
\hline Foco & $\begin{array}{l}\text { Chandler and Jansen (1992); Man et al. (2008); Morris et al. } \\
\text { (2013) }\end{array}$ \\
\hline Gestão & Man and Lau (2002); Mitchelmore and Rowley (2010) \\
\hline Inovação & Man et al. (2008); Morris et al. (2013) \\
\hline Oportunidade & $\begin{array}{l}\text { Chandler and Jansen (1992); Kyndt and Baert (2015); Man and } \\
\text { Lau (2002); Man et al. (2008); Mitchelmore and Rowley } \\
\text { (2010); Morris et al. (2013); }\end{array}$ \\
\hline Perseverança & Kyndt and Baert (2015); Morris et al. (2013) \\
\hline Persuasão & Kyndt and Baert (2015); Morris et al. (2013) \\
\hline Relacionamento & $\begin{array}{l}\text { Chandler and Jansen (1992); Kyndt and Baert (2015); Man and } \\
\text { Lau (2002); Man et al. (2008); Mitchelmore and Rowley } \\
\text { (2010); Morris et al. (2013) }\end{array}$ \\
\hline Técnicas & Chandler and Jansen (1992); Man et al. (2008) \\
\hline
\end{tabular}




\subsection{Ensino de Empreendedorismo}

Embora não exista uma definição dos objetivos do ensino de empreendedorismo, Mwasalwiba (2011), em sua revisão de literatura identificou os principais termos utilizados como objetivos do ensino de empreendedorismo, tais como o desenvolvimento de habilidades, intenções, comportamentos empreendedores, a identificação de oportunidades, o aumento do espírito empreendedor, o desenvolvimento de uma cultura empreendedora, a criação e gestão de novos negócios e a contribuição com a sociedade. Ainda, Rocha e Freitas (2014) identificaram que o objetivo do ensino de empreendedorismo deve ser levar o aluno a entender o que é empreendedorismo, a desenvolver sua capacidade de ser criativo e inovar, de descobrir oportunidades, de planejar novos negócios, de assumir riscos, de tomar decisões, de trabalhar em equipe, de administrar o negócio e de aprender com os erros.

Neck e Greene (2011) apresentam diferentes perspectivas acerca do ensino de empreendedorismo. A primeira delas é a centrada nas características e comportamentos do empreendedor, indicando suas caraterísticas de sucesso. Os alunos podem se identificar ou não com os perfis apresentados, o que pode acabar gerando desmotivação, caso o aluno não enxergue que possui as características necessárias para ser bem-sucedido. A perspectiva de processo considera o empreendedorismo como algo linear e previsível, que pode ser ensinado desde a criação até a extinção da empresa. Já na abordagem de processo cognitivo, o foco está no entendimento do processo de decisão e dos modelos mentais adotados pelo empreendedor. Por fim, a perspectiva de empreendedorismo como método sugere que empreendedorismo não é previsível e demanda ação. Por isso, não é suficiente compreender os conceitos de empreendedorismo e como empreendedores pensam, mas é necessário usar uma série de práticas que levem os alunos a agir e a criar.

O ensino de empreendedorismo é fundamentado em outras disciplinas, tendo um caráter multidisciplinar que direciona para temas como identificação, avaliação e exploração de oportunidades, Design Thinking, modelagem de negócios, desenvolvimento de clientes e da proposta de valor, prototipagem e validação da ideia de negócio com stakeholders (Neck, Greene \& Brush, 2014).

Por isso, as novas abordagens de ensino de empreendedorismo têm se apoiado na teoria effectuation e conceitos como lean startup e customer development para propor novas técnicas e experiências de ensino (Sá \& Kretz, 2015). De acordo com a lógica effecutal, o empreendedor inicia o processo com uma ideia, define o que pretende fazer e quanto está disposto a perder e passa a interagir com potenciais stakeholders para identificar se devem alterar sua ideia de negócio ou se comprometer com ela (Sarasvathy, 2001).

Segundo Steve Blank (2013) a metodologia Lean Startup estimula a experimentação ao invés do planejamento excessivo, a obtenção de feedback e insights do cliente, no lugar de suposições e intuições e um processo de Design Thinking iterativo. Por isso, exige que o empreendedor saia da falácia da criação do plano de negócios e esteja disposto a testar e validar sua ideia de negócios com possíveis clientes.

A partir desses conceitos, Sá e Kretz (2015) identificaram que no lugar de plano de negócios, os alunos são estimulados a desenvolver um quadro de modelo de negócios chamado Business Model Canvas. O Canvas é um quadro com nove áreas que resume as principais

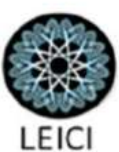


informações e decisões sobre proposta de valor, segmentos de mercado, relacionamento com clientes, canais, parcerias chave, atividades chave, recursos chave, estrutura de custos e fontes de receita do negócio (Osterwalder \& Pigneur, 2010). Ainda, os alunos devem utilizar protótipos ou produtos mínimos viáveis com possíveis clientes, fornecedores, fabricantes e parceiros para obter feedbacks, refletir e fazer as mudanças necessárias no produto/serviço proposto (Ries, 2011).

Ainda, percebe-se um movimento de adoção desses conceitos por parte dos professores de empreendedorismo, que utilizam o canvas, competições de pitch, workshops intensivos e até mesmo comunidades para que os alunos possam aprender empreendedorismo ao criar e não apenas de forma teórica (Sá \& Kretz, 2015).

Rocha e Freitas (2014) identificaram que os principais métodos e técnicas utilizados para o ensino de empreendedorismo são: trabalhos em grupo, grupos de discussão, brainstorming, provas, filmes e vídeos, seminários com empreendedores, criação de empresas e competição de planos de negócios. Salusse e Andreassi (2016) identificaram as principais metodologias de ensino embasadas na teoria effectuation: aulas expositivas, estudos de caso, palestrantres convidados, coaching, simulação, dinâmicas, jogos, vídeos, ferramentas de diagnóstico, pitch, mídias sociais, design thinking, storytelling, reflexão sobre a prática, desafios, testes de hipóteses, consultoria e viagens a campo. Percebe-se que as metodologias mais tradicionais se misturam com as emergentes.

Apesar do consenso sobre a importância metodologias que tratem de teste de hipóteses (Ries, 2011), modelagem de negócios (Osterwalder \& Pigneur, 2010) e desenvolvimento de clientes (Blank \& Dorf, 2012), não existem avaliações comprovando que o uso dessas metodologias no ensino é efetivo, pois não existe número suficiente de pesquisas comparando diferentes métodos de ensino (Fayolle, 2013).

Nabi, Lina, Fayolle, Krueger e Wamsley (2017) identificaram, a partir de sua revisão de literatura que os principais indicadores dos efeitos do ensino de empreendedorismo pesquisados são: atitudes, conhecimentos, intenção de empreender, número de empresas criadas e desempenho das empresas existentes. Considerando que os resultados de aprendizagem esperados do ensino de empreendedorismo são a aquisição de competências (Man, 2012), é necessário identificar se os cursos e disciplinas estão sendo capazes de desenvolver as competências desejadas.

\section{Método}

\subsection{O curso}

O curso que subsidiou a construção da escala de competências tem trinta e duas horas de duração, com oito encontros de quatro horas cada. Todos os alunos, professores e servidores da Universidade podiam participar do mesmo. Ele foi criado com o objetivo de facilitar o desenvolvimento de competências empreendedoras na Universidade;

O curso acontece uma vez por semestre e cento e sessenta vagas são ofertadas, divididas em quatro turmas com quarenta vagas cada. Cada turma é conduzida por um professor, todos eles vinculados ao Centro de Empreendedorismo e Incubação da UFG e alunos ou egressos da

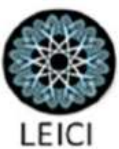


linha de pesquisa em Estratégia, Empreendedorismo e Inovação do Programa de PósGraduação em Administração da Universidade.

O curso contempla uma carga horária de 32 horas e os conteúdos abordados são o O que é Empreendedorismo e Comportamento Empreendedor (4 horas), Criatividade (4 horas), Design Thinking e Lean Startup (8 horas), Canvas (10 horas) e Pitch (2 horas) e uma banca final de apresentação de todos os projetos (aula conjunta com todas as turmas, com duração de 4 horas). Segundo os objetivos descritos nos materiais do curso, ao final do mesmo espera-se que os alunos sejam capazes de: avaliar quais competências empreendedoras possui e quais precisa desenvolver; trabalhar em equipe; elaborar um modelo de negócios; defender qual é a proposta de valor do negócio escolhido; validar o modelo de negócios com possíveis clientes, fornecedores e parceiros usando ferramentas de Design Thinking e Lean Startup; vender sua ideia de negócio para outras pessoas mesmo sob pressão.

Na primeira aula do curso é feita a apresentação de todos os estudantes por meio de uma dinâmica e um ou dois empreendedores convidados participam relatando sua história e, principalmente as dificuldades e erros cometidos ao empreender. A discussão das competências que um empreendedor tem ou deve ter é feita a partir dessas reflexões. Em seguida, são apresentados alguns conceitos de empreendedorismo e é proposto um desafio para os alunos. Eles recebem $\mathrm{R} \$ 20,00$ e tem uma semana para multiplicar o dinheiro, da forma que escolherem, desde que não realizem atividades ilegais ou citem o nome da Universidade.

$\mathrm{Na}$ aula seguinte, são apresentados conteúdos de criatividade, com atividades práticas que tiram o aluno de sua zona de conforto. Então, são apresentados os conceitos de Design Thinking e Lean Startup e, a partir da identificação de um problema real, os alunos têm uma ideia de negócio que será trabalhada ao longo de todo o curso. Atividades teóricas e práticas são alternadas para que ao final do curso os alunos tenham um modelo de negócios validado que é apresentado e avaliado em uma seção de Pitch. As três melhores ideias são selecionadas e premiadas.

\subsection{Desenvolvimento da escala de competências}

Para ampliar a compreensão do curso e seus objetivos foram conduzidos dois grupos focais. O primeiro grupo focal foi realizado com os três professores do curso e com o coordenador do núcleo de inovação tecnológica da Universidade. Seu objetivo foi identificar quais competências empreendedoras o curso pretendia desenvolver e quais eram os objetivos educacionais de cada atividade realizada. O grupo focal foi gravado, após autorização dos participantes e teve duração de cinquenta e três minutos. Além disso, todos os objetivos instrucionais das atividades do curso foram transcritos para consulta posterior.

O segundo grupo focal foi realizado com seis estudantes, egressos do curso, que participaram das turmas do primeiro semestre de 2016. Seu objetivo era identificar quais competências empreendedoras foram, de fato, desenvolvidas ao longo do curso. Inicialmente, foi apresentada a definição de competência empreendedora, solicitando que os alunos escrevessem individualmente em uma folha em branco as competências que acreditavam ter desenvolvido no curso. Essa atividade teve vinte e cinco minutos de duração. Em seguida, cada aluno leu o que escreveu e foi feita uma discussão em grupo. A segunda etapa durou quarenta

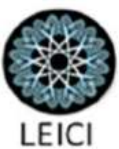


e dois minutos. O grupo focal também foi gravado, mediante autorização dos participantes e as folhas foram mantidas para consulta posterior.

A análise dos dados foi feita a transcrição e leitura flutuante de todo o material proveniente dos grupos focais, permitindo a categorização e elaboração dos itens (Bardin, 1989). As categorias foram definidas a posteriori, a partir da análise do corpus de 34 páginas e 10.413 palavras e deram origem às dimensões que compuseram a versão inicial do instrumento com 40 itens: relacionamento, comunicação, assumir riscos, aceitar erros, modelagem de negócios, compreensão dos clientes.

\subsection{Validação da Escala}

O instrumento em sua versão inicial com 40 itens foi submetido à análise de juízes especialistas para identificar sua adequação. Atuaram como juízes dois professores e pesquisadores de empreendedorismo e uma especialista em construção de instrumentos de medida. Inicialmente, os juízes indicaram a qual dimensão acreditavam que cada item pertencia. Os itens que tiveram concordância entre os juízes foram mantidos nas respectivas dimensões. Em seguida foi realizada uma análise qualitativa dos dados, junto a três juízes. Todos os itens foram analisados para identificar sua pertinência e semântica. Alguns itens foram excluídos e outro reescritos, segundo sugestões. Algumas dimensões inicialmente propostas também foram alteradas, conforme a sugestão dos juízes, passando a existir as seguintes dimensões: competências para trabalhar em equipe, vender a ideia de negócio, assumir riscos de insucesso, aceitar erros, elaborar modelo de negócio e identificar oportunidades a partir de demanda dos clientes.

Em seguida, a escala foi submetida à análise semântica, da qual participaram outros quatro estudantes, egressos do curso, também das turmas do primeiro semestre de 2016. $\mathrm{O}$ instrumento foi apresentado para os alunos já em seu formato digital. Foi solicitado que eles respondessem todas as perguntas e ao final informassem se houve alguma dificuldade de compreensão dos itens ou das instruções. Dois alunos fizeram sugestões para melhorar a compreensão da instrução inicial, que foram incorporadas à versão final do instrumento, agora com seis dimensões e trinta e seis itens.

Para validação empírica da escala, a mesma foi aplicada com os egressos do curso do segundo semestre de 2016 e primeiro semestre de 2017. No segundo semestre de 2016, 145 alunos concluíram o curso e 81 responderam o questionário de competências, obtendo uma taxa de resposta de 55\%. Já no primeiro semestre de 2017, 152 alunos concluíram o curso e 102 deles responderam o questionário, obtendo uma taxa de resposta de $67 \%$.

As 182 respostas numéricas válidas foram submetidas a análises fatoriais exploratórias e de consistência interna com uso do software SPSS, versão 20. Utilizou-se como critério do tamanho amostral a proposta de Hair et al. (2005), que considera como necessário que o número de respondentes seja no mínimo cinco vezes o número das variáveis do instrumento.

Inicialmente, o banco de dados foi examinado para verificação de dados ausentes. Como o percentual de casos ausentes era inferior a 5\%, foi feita a substituição dos valores pela média (Hair et al., 2005). Foi feita, ainda, uma análise da correlação de Pearson entre as variáveis. Pelos valores obtidos, nota-se que não há forte correlação linear entre as variáveis. Desta forma, infere-se que as variáveis são de certa forma correlacionadas linearmente, porém esta

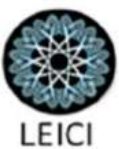


associação não é forte a ponto de ser problemática e haver a necessidade de excluir variáveis da análise.

Finalmente, para se verificar se a análise fatorial é uma técnica adequada para a análise dos dados, foram conduzidos testes para identificar a fatorabilidade da matriz. $\mathrm{O}$ valor do teste KMO $(0,922)$ é considerado meritório e o teste de esfericidade de Bartlett indica a fatorabilidade da matriz ( $\mathrm{sig}=0,001$ ) (Hair et al., 2005).

A análise de comunalidades mostrou que nenhum item apresentou valores extremos (próximos de 0 ou 1). Os resultados da análise de componentes principais indicaram 7 autovalores (eigenvalues) maiores que $1 \mathrm{com}$ apenas seis deles explicando mais do que $3 \%$ da variância. Ao se inspecionar o gráfico de sedimentação scree plot, notou-se que são indicados dois componentes, uma vez que é neste ponto que é observada uma quebra da curva, ficando os demais componentes lado a lado. Ainda, a análise paralela realizada indicou a extração de três fatores. Como trata-se de uma análise exploratória da estrutura, foram testadas estruturas $\operatorname{com} 2,3,4,5,6$ e 7 por meio do método PAF e rotação Promax para identificar qual está mais ajustada à teoria sobre o tema, conforme recomendado por Hair et al (2005).

A extração de 5 fatores foi considerada a mais adequada, pois as escalas possuem conteúdo compatível com a literatura científica sobre o tema. Foram consideradas cargas fatoriais superiores a 0.45, de acordo com a recomendação de Tabachnick \& Fidell 2013). Os resultados são apresentados na Tabela 2 . O fator 1 foi denominado "competências para elaborar o modelo de negócios" $(\alpha=0,95)$. O fator 2 foi denominado "competências para vender e assumir riscos" $(\alpha=0,89)$. O fator 3 é chamado de "competências para identificação de oportunidades" $(\alpha=0,89)$. O fator 4 foi chamado de "competências para aceitar erros" $(\alpha=$ $0,87)$. Por fim, o fator 5 foi chamado de "competências de trabalho em equipe" $(\alpha=0,83)$.

Tabela 2

\begin{tabular}{|c|c|c|c|c|c|}
\hline Fator & Item & $\mathbf{M}$ & DP & Cargas & $h_{2}$ \\
\hline \multirow{7}{*}{$\begin{array}{l}\text { Competências } \\
\text { para elaborar o } \\
\text { modelo de } \\
\text { negócios } \\
(\text { Alpha }=0,948)\end{array}$} & $\begin{array}{l}\text { Defendo qual é a proposta de valor do } \\
\text { meu negócio. }\end{array}$ & 8,25 & 1,480 & 0,568 & 0,669 \\
\hline & $\begin{array}{l}\text { Demonstro quais são os benefícios do } \\
\text { meu produto/serviço. }\end{array}$ & 8,46 & 1,268 & 0,639 & 0,694 \\
\hline & $\begin{array}{l}\text { Demonstro como as diversas áreas de meu } \\
\text { negócio estão relacionadas. }\end{array}$ & 8,12 & 1,377 & 0,674 & 0,616 \\
\hline & $\begin{array}{l}\text { Avalio corretamente o(s) segmento(s) de } \\
\text { cliente(s) que será(ao) atendido(s) pelo } \\
\text { meu negócio. }\end{array}$ & 8,02 & 1,520 & 0,628 & 0,618 \\
\hline & $\begin{array}{l}\text { Escolho os canais que serão utilizados } \\
\text { para que o produto chegue até o cliente. }\end{array}$ & 8,21 & 1,462 & 0,707 & 0,651 \\
\hline & $\begin{array}{l}\text { Concebo estratégias de relacionamento } \\
\text { com o cliente. }\end{array}$ & 8,17 & 1,601 & 0,758 & 0,587 \\
\hline & $\begin{array}{l}\text { Declaro quais são as fontes de receita do } \\
\text { meu negócio. }\end{array}$ & 7,76 & 1,862 & 0,629 & 0,511 \\
\hline
\end{tabular}


Formulo quais são as atividades

necessárias para que o negócio possa $8,09 \quad 1,560 \quad 0,640 \quad 0,631$

funcionar.

\begin{tabular}{|c|c|c|c|c|}
\hline $\begin{array}{l}\text { Investigo quais são os recursos } \\
\text { necessários para a execução do negócio. }\end{array}$ & 7,93 & 1,572 & 0,791 & 0,619 \\
\hline $\begin{array}{l}\text { Identifico as parcerias necessárias para } \\
\text { otimizar o negócio. }\end{array}$ & 7,95 & 1,602 & 0,837 & 0,65 \\
\hline $\begin{array}{l}\text { Declaro quais são as fontes de custo do } \\
\text { meu negócio. }\end{array}$ & 7,88 & 1,585 & 1,003 & 0,695 \\
\hline $\begin{array}{l}\text { Identifico oportunidades de negócios a } \\
\text { partir de expectativas dos clientes. }\end{array}$ & 8,12 & 1,540 & 0,564 & 0,637 \\
\hline $\begin{array}{l}\text { Vendo minha ideia de negócio para outras } \\
\text { pessoas mesmo sob pressão. }\end{array}$ & 7,55 & 1,905 & 0,485 & 0,545 \\
\hline Apresento as minhas ideias com clareza. & 7,80 & 1,514 & 0,700 & 0,67 \\
\hline Sinto-me confiante para falar em público. & 7,49 & 2,273 & 0,600 & 0,485 \\
\hline $\begin{array}{l}\text { Defendo minha ideia de negócio para } \\
\text { outras pessoas de forma objetiva. }\end{array}$ & 7,81 & 1,691 & 0,839 & 0,759 \\
\hline $\begin{array}{l}\text { Respondo com segurança perguntas de } \\
\text { outras pessoas sobre o meu negócio. }\end{array}$ & 7,90 & 1,646 & 0,689 & 0,624 \\
\hline $\begin{array}{l}\text { Participo de atividades que simulam } \\
\text { riscos de insucesso. }\end{array}$ & 7,06 & 2,213 & 0,631 & 0,471 \\
\hline $\begin{array}{l}\text { Realizo tarefas que estão fora da minha } \\
\text { zona de conforto. }\end{array}$ & 7,94 & 1,893 & 0,413 & 0,382 \\
\hline $\begin{array}{l}\text { Exponho minhas ideias a outras pessoas, } \\
\text { sem medo de ser julgado (a). }\end{array}$ & 8,01 & 1,864 & 0,572 & 0,424 \\
\hline $\begin{array}{l}\text { Crio produtos/serviços a partir das } \\
\text { opiniões do potencial cliente. }\end{array}$ & 7,90 & 1,778 & 0,516 & 0,677 \\
\hline $\begin{array}{l}\text { Crio protótipos para validar meu } \\
\text { produto/serviço com o potencial cliente. }\end{array}$ & 7,76 & 1,804 & 0,878 & 0,69 \\
\hline $\begin{array}{l}\text { Desenvolvo um produto mínimo viável } \\
\text { para testar o produto junto ao potencial } \\
\text { cliente. }\end{array}$ & 7,48 & 1,977 & 0,907 & 0,749 \\
\hline $\begin{array}{l}\text { Valido minha ideia de negócio com } \\
\text { potenciais clientes antes de executá-la. }\end{array}$ & 7,96 & 1,736 & 0,847 & 0,689 \\
\hline $\begin{array}{l}\text { Valido minha ideia de negócio com } \\
\text { potenciais parceiros-chave antes de } \\
\text { executá-la. }\end{array}$ & 7,57 & 1,830 & 0,603 & 0,453 \\
\hline
\end{tabular}

Competências para vender e assumir riscos $($ Alpha $=0,890)$

Competências para

identificação de oportunidades $($ Alpha $=0,888)$

Investigo quais são os recursos

Identifico as parcerias necessárias para

otimizar o negócio.

Declaro quais são as fontes de custo do meu negócio.

Identifico oportunidades de negócios a

Vendo minha ideia de negócio para outras pessoas mesmo sob pressão. 


\begin{tabular}{|c|c|c|c|c|c|}
\hline \multirow{5}{*}{ 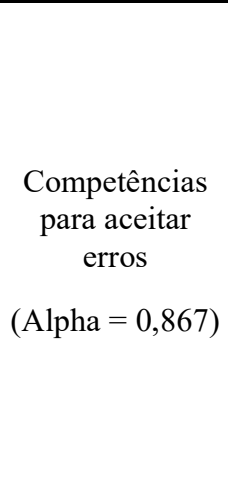 } & $\begin{array}{l}\text { Recordo-me de erros que cometi no } \\
\text { passado. }\end{array}$ & 8,05 & 1,752 & 0,713 & 0,536 \\
\hline & $\begin{array}{l}\text { Identifico erros cometidos por outras } \\
\text { pessoas ao tentar empreender. }\end{array}$ & 8,24 & 1,360 & 0,762 & 0,554 \\
\hline & $\begin{array}{l}\text { Extraio lições dos erros cometidos por } \\
\text { mim. }\end{array}$ & 8,35 & 1,668 & 0,807 & 0,718 \\
\hline & $\begin{array}{l}\text { Extraio lições dos erros cometidos por } \\
\text { outras pessoas. }\end{array}$ & 8,25 & 1,527 & 0,877 & 0,696 \\
\hline & $\begin{array}{l}\text { Concluo que erros fazem parte do } \\
\text { processo empreendedor. }\end{array}$ & 9,05 & 1,327 & 0,540 & 0,434 \\
\hline \multirow{5}{*}{ 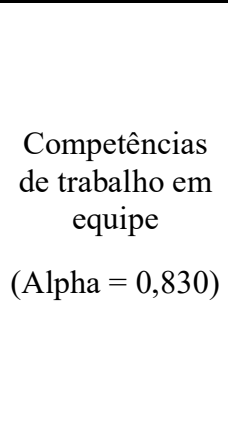 } & $\begin{array}{l}\text { Trabalho de forma cooperativa para que a } \\
\text { equipe possa alcançar resultados. }\end{array}$ & 8,43 & 1,404 & 0,810 & 0,668 \\
\hline & $\begin{array}{l}\text { Identifico como cada membro pode } \\
\text { contribuir para o alcance dos resultados. }\end{array}$ & 7,93 & 1,622 & 0,683 & 0,498 \\
\hline & $\begin{array}{l}\text { Divido as tarefas entre os membros } \\
\text { segundo os potenciais de cada um. }\end{array}$ & 7,80 & 1,783 & 0,605 & 0,522 \\
\hline & Aceito opiniões diferentes das minhas. & 8,62 & 1,388 & 0,653 & 0,433 \\
\hline & Concilio opiniões distintas. & 8,33 & 1,560 & 0,521 & 0,477 \\
\hline \multicolumn{6}{|c|}{ \% variância total explicada $=64,677$} \\
\hline $\mathrm{N}=182$ & & & & & \\
\hline
\end{tabular}

\section{Discussão}

$\mathrm{O}$ ensino de empreendedorismo pretende estimular o estudante a entender o funcionamento do mercado na vida real, desenvolver habilidades para conceber e testar novas ideias, identificar oportunidades, avaliar um novo negócio, avaliar e dimensionar os riscos do negócio pretendido, construir a habilidade de aprender de forma coletiva, de atuar em equipe, de passar e receber críticas construtivas (Rocha \& Freitas, 2014).

Ainda, as metodologias baseadas na teoria effectual ajudam o aluno a desenvolver diversas versões de um produto ou serviço para chegar na versão ideal, a criar e testar protótipos, a procurar reduzir riscos, comprometendo apenas uma quantidade limitada de recursos para o negócio de cada vez, a responder a novas oportunidades e a saber se apresentar e negociar (Salusse \& Andreassi, 2016).

Ao utilizar o Business Model Canvas e testar suas hipóteses semanalmente, os alunos descobrem se os possíveis clientes iriam de fato comprar seus produtos e conseguem desenvolver melhor seu processo de criação da empresa (Sá \& Kretz, 2015). Dessa forma, percebe-se que a escala de competências empreendedoras elaborada possui evidências de validade para mensurar o quanto o aluno é competente em cada uma dessas dimensões, apresentando uma solução para as lacunas apontadas por Fayolle (2013) e Nabi et al. (2017) 
que indicam que os efeitos do ensino de empreendedorismo são pesquisados principalmente por meio das intenções de empreender. A escala apresentada é, portanto, uma alternativa de avaliação, que será baseada em aprendizagem e comportamento e não apenas em intenção de iniciar o próprio negócio.

\section{Conclusão}

A literatura sobre competências empreendedoras é extensa, porém focada nas competências que os empreendedores que já iniciaram seus negócios possuem ou deveriam possuir. $\mathrm{O}$ estudo faz contribuições à literatura sobre ensino de empreendedorismo ao levantar competências empreendedoras que podem ser desenvolvidas por meio de cursos ou disciplinas de empreendedorismo e ao propor uma escala de avaliação das mesmas, que pode ser utilizada como instrumento para mensurar se os cursos e disciplinas de empreendedorismo estão alcançando os objetivos esperados.

Ainda, a escala apresentada está de acordo com os movimentos recentes de transformação do ensino de empreendedorismo que, embasados na teoria effectuation e conceitos e ferramentas como Lean Startup, Design Thinking, modelagem de negócios com Canvas e desenvolvimento de clientes, recomendam que a aprendizagem ocorra por meio da prática e criação. Dessa forma, poderá ser utilizada para avaliação de diversos cursos e disciplinas que vem surgindo no mundo todo utilizando essas novas abordagens.

A descrição dos conteúdos, objetivos e características do curso possibilitam que os interessados em aplicar a escala desenvolvida identifiquem se o curso ou disciplina que pretendem avaliar são similares ao descrito nesse artigo, garantido que seu uso é adequado. Além disso, o processo de construção e validação da escala de competências empreendedoras desenvolvidas por um curso de extensão universitária pode ser replicado para o desenvolvimento de escalas que pretendam avaliar os efeitos de outros cursos ou disciplinas.

Como limitações, aponta-se que a escala foi elaborada a partir da análise dos materiais e de grupos focais com alunos, professores e coordenadores de apenas um curso. Sugere-se realizar processo similar com outros cursos.

Ainda, é sugerido que o instrumento seja aplicado em pré e pós-testes para avaliar a mudança nas competências empreendedoras do aluno antes e depois do curso, tornando-se uma forma de avaliar se os resultados e objetivos do curso estão sendo alcançados. É recomendável realizar mais de um pós-teste, pois segundo Ployhart e Vanderberg (2010) o uso de duas medidas só fornece uma visão linear da mudança. Pode-se aplicar o instrumento logo após o término do curso, três meses após o término e assim por diante, para identificar se o aumento ou redução das competências empreendedoras se mantém ao longo do tempo.

Por fim, podem ser feitas comparações entre grupos de alunos, para identificar se existem diferenças de competências de acordo com gênero, idade, experiências anteriores, participação em movimentos estudantis e outros.

\section{Referências}

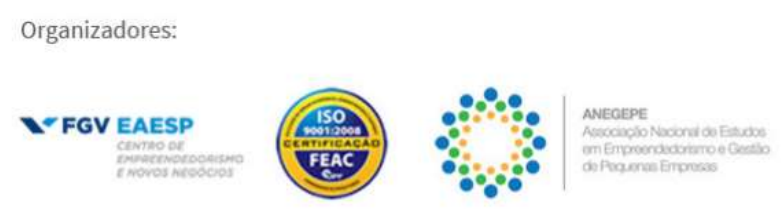

Realizadores:
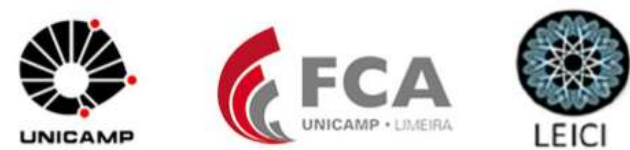
Bird, B. (1995). Toward a theory of entrepreneurial competency. Advances in Entrepreneurship Firm Emergence and Growth, 2, 51-72.

Blank, S., \& Dorf, B. (2012). The startup owner's manual: the step-by-step guide for building a great company. Pescadero, CA: K\&S Ranch Publishing.

Chandler, G. N., \& Jansen, E. (1992). The founder's self-assessed competence and venture performance. Journal of Business Venturing, 7, 223-236.

Fayolle, A. (2013). Personal views on the future of entrepreneurship education. Entrepreneurship \& Regional Development, 25(7-8), 672-701.

Hair, J. F., Black, W. C., Babin, B. j., Anderson, R. E. (2010). Multivariate data analysis (7th ed.). Prentice Hall.

Kyndt, E., \& Baert, H. (2015). Entrepreneurial competencies: Assessment and predictive value for entrepreneurship. Journal of Vocational Behavior, 90, 13-25

Man, T. W. Y., Lau, T., \& Chan, K. F. (2002). The competitiveness of small and medium enterprises: A conceptualization with focus on entrepreneurial competencies. Journal of Business Venturing, 17, 123-142.

Man, T. W. Y., Lau, T., \& Snape, E. (2008). Entrepreneurial Competencies and the Performance of Small and Medium Enterprises: An Investigation through a Framework of Competitiveness. Journal of Small Business \& Entrepreneurship, 21(3), 257-276.

Man, T. W. Y. (2012). Developing a behaviour-centred model of entrepreneurial learning. Journal of Small Business and Enterprise Development, 19(3), 549-566.

Mitchelmore, S., \& Rowley, J. (2010). Entrepreneurial competencies: a literature review and development agenda. International Journal of Entrepreneurial Behavior \& Research, 16(2), 91-111.

Morris, M. H., Webb, J. W., Fu, J. \& Singhal, S. (2013). A Competency-Based Perspective on Entrepreneurs Education: Conceptual and Empirical Insights. Journal of Small Business Management, 51(3), 352-369.

Mwasalwiba, E. S. (2011). Entrepreneurship education: a review of its objectives, teaching methods, and impact indicators. Education + Training, 52(1), 20-47.

Nabi, G., Linan, F., Fayolle, A., Krueger, N., Wamsley, A. (2017). The impact of entrepreneurship education in higher education: a systematic review and research agenda. Academy of Management Learning \& Education, 16(2), 277-299.

Neck, H.M., \& Greene, P. G. (2011). Entrepreneurship Education: Known Worlds and New Frontiers. Journal of Small Business Management, 49(1), 55-70.

Neck, H.M., Greene, P. G., \& Brush, C. G. (2014). Teaching Entrepreneurship: a PraticeBased Approach. Northampton, MA: Edward Elgar Publishing.

Osterwalder, A., \& Pigneur, Y. (2010). Business model generation. Hoboken, New Jersey: John Wliey \& Sons, Inc.

Ployart, R. E.\& Vanderberg, R. J. (2010). Longitudinal research: The theory, design, and analysis of change. Journal of Management, 36(1), 94-120.

Ries, E. (2011). The lean startup: how today's entrepreneurs use continuous innovation to create radically successful businesses. New York, NY: Crown Publishing.

Rocha, E. L. C., \& Freitas, A. A. F. (2014). Avaliação do Ensino de Empreendedorismo entre Estudantes Universitários por meio do Perfil Empreendedor. Revista de Administração Comtemporânea, 18(4), 465-486.

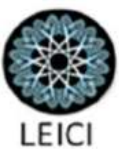


Sá, C. M., \& Kretz, A. J. (2015). The Entrepreneurship Movement and the University. New York, NY: Palgrave Macmillan.

Salusse, M. A. Y., \& Andreassi, T. (2016). O Ensino de Empreendedorismo com Fundamento na Teoria Effectuation. Revista de Administração Comtemporânea, 20(3), 305-327.

Sarasvathy, S. D. (2001a). Causation and effectuation: toward a theorial shift from economic inevitability to entrepreneurial contigency. Academy of Management Review, 26(2), 243263. 


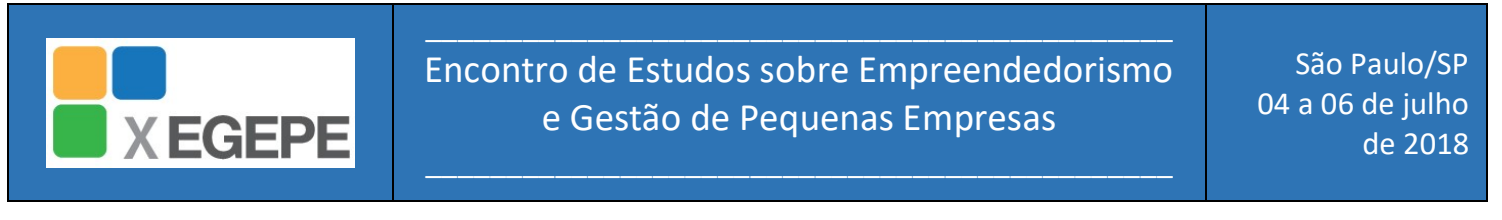

